$04 ; 11$

\title{
Механизм полевой эмиссии электронов с туннельно-тонким алмазным покрытием на автокатоде
}

\author{
(C) P.K. Яфраров \\ Саратовский фрилиал Института радиотехники и электроники им. В.А. Котельникова РАН, Саратов, Россия \\ E-mail: pirpc@yandex.ru
}

Поступило в Редакцию 20 февраля 2020 г.

В окончательной редакции 28 февраля 2020 г.

Принято к публикации 3 марта 2020г.

\begin{abstract}
Исследованы автоэмиссионные характеристики катодных матриц на основе нанокомпозитных алмазографитовых пленочных структур с упрочняющим туннельно-тонким алмазным покрытием. Показано, что автоэмиссионные характеристики не связаны с морфологией эмитирующей поверхности и не могут быть объяснены в рамках модели Фаулера и Нордгейма. Установлено влияние толщины алмазного покрытия на автоэмиссионные характеристики и электрическую прочность катодной гетероструктуры. Интерпретация полученных закономерностей основана на увеличении прозрачности потенциальных барьеров для туннелирования электронов за счет уменьшения сил зеркального изображения.
\end{abstract}

Ключевые слова: алмазографитовый нанокомпозит, автоэмиссия, туннельно-тонкая алмазная пленка.

DOI: 10.21883/PJTF.2020.10.49432.18253

Актуальной задачей твердотельной электроники является получение высокоэффективных деградационностойких автоэмиссионных катодов для плоских информационных дисплеев, энергосберегающих светотехнических устройств, приборов и устройств вакуумной СВЧ-электроники и др. Это обусловлено сложностью условий их эксплуатации. Стабильность автоэмиссионных характеристик чрезвычайно чувствительна к изменению микрогеометрии катода и состоянию его поверхности. К эффектам, влияющим на стабильность автоэмиссии, относятся катодное распыление, изменение работы выхода электронов, локальные разогревы, механические напряжения в материале эмиттера и др.

Перспективными для создания автоэмиссионных катодов являются наноуглеродные материалы [1-3]. Они устойчивы к высокотемпературному нагреву и бомбардировке ионами остаточных газов, которые имеют место в приборах, работающих в условиях технического вакуума и высоковольтного питания. Кроме того, при определенных структурных модификациях, характерных для алмазного типа гибридизации связей валентных электронов атомов углерода и „открытых“ углеродных нанотрубок с графитовым типом структуры, они имеют более низкую, чем массивный углеродный материал, работу выхода электронов. Это уменьшает электрофизическую нагрузку на материал автокатодов и позволяет получать высокие плотности автоэмиссионных токов при более продолжительном ресурсе эксплуатации.

Идеальными электрофизическими свойствами для применения в качестве долговечных высокостабильных автоэмиссионных катодов обладает нанокристаллический алмаз. У него помимо традиционных свойств алмаза, присущих массивному кристаллическому состоянию, таких как низкий коэффициент катодного распыления, отрицательное электронное сродство, высокие теплопроводность, электрическая и механическая прочность и др., присутствуют квантовые эффекты, характерные для низкоразмерных систем. Благодаря этим свойствам сотрудниками Аргоннской национальной лаборатории (США) показано, что нанокристаллические алмазные покрытия наноострий и пленки, полученные с использованием неравновесной микроволновой плазмы, способны обеспечивать чрезвычайно высокую плотность тока (до 60-100 $\mu \mathrm{A}$ на острие!) и стабильность.

Целью настоящей работы является исследование возможности улучшения автоэмиссионных характеристик и увеличения ресурса эксплуатации полевых источников электронов на основе нанокомпозиционных алмазографитовых структур.

Получение нанокомпозиционных алмазографитовых пленочных структур на поликоровых и стеклянных подложках осуществлялось с использованием СВЧ ионноплазменного источника, описанного в работе [4]. Мощность СВЧ-излучения и индукция магнитного поля составляли соответственно $250 \mathrm{~W}$ и $875 \mathrm{G}$. Процесс осуществлялся при температуре подложки $300^{\circ} \mathrm{C}$ и давлении паров этанола около $0.05 \mathrm{~Pa}$. Потенциал смещения $\left(U_{b}\right)$ на подложкодержателях в процессах осаждения наноалмазографитовых покрытий составлял $+250 \mathrm{~V}$. На полученные покрытия толщиной $50-70 \mathrm{~nm}$ осаждались туннельно-тонкие алмазные пленки. Осаждение проводилось в микроволновой плазме при температуре подложки $300^{\circ} \mathrm{C}$ и давлении паров этанола около $0.1-0.3 \mathrm{~Pa}$. Потенциал смещения $U_{b}$ в процессах осаждения алмазных покрытий составлял $-300 \mathrm{~V}$.

Морфология наноалмазографитовых и алмазных пленочных покрытий изучалась с использованием сканирующего атомно-силового микроскопа (АСM) 

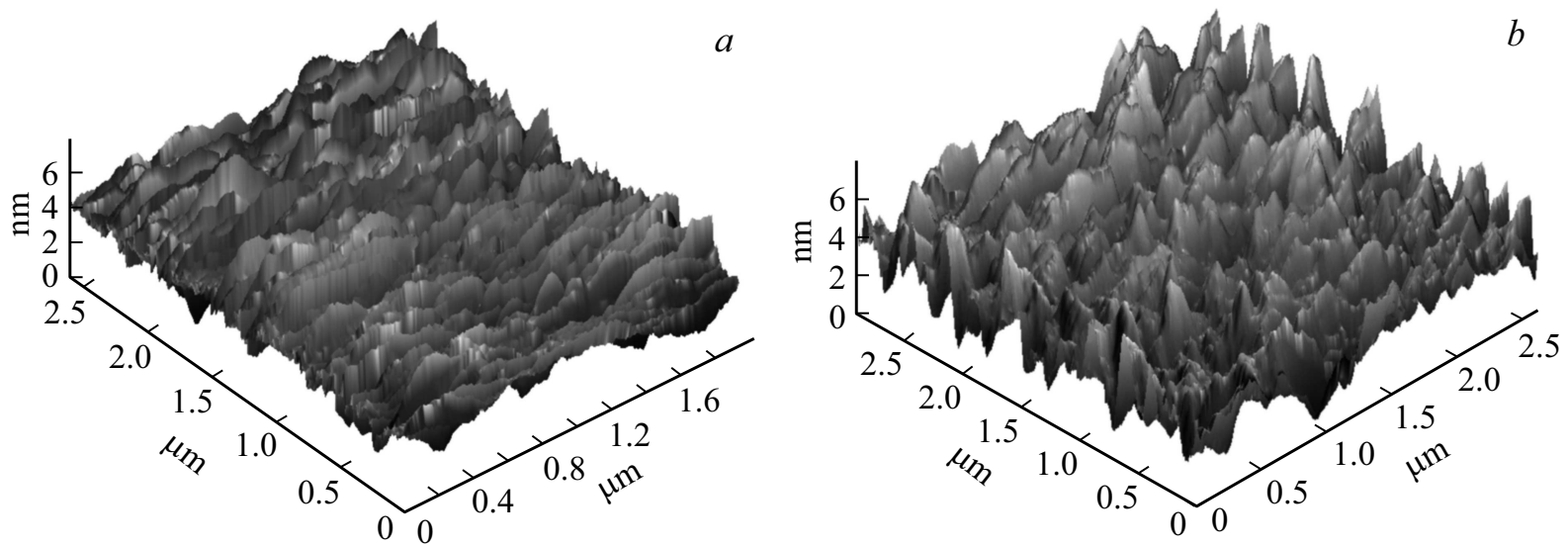

Рис. 1. АСМ-изображения морфологии наноалмазографитовой пленочной структуры до $(a)$ и после $(b)$ осаждения на нее алмазной пленки.
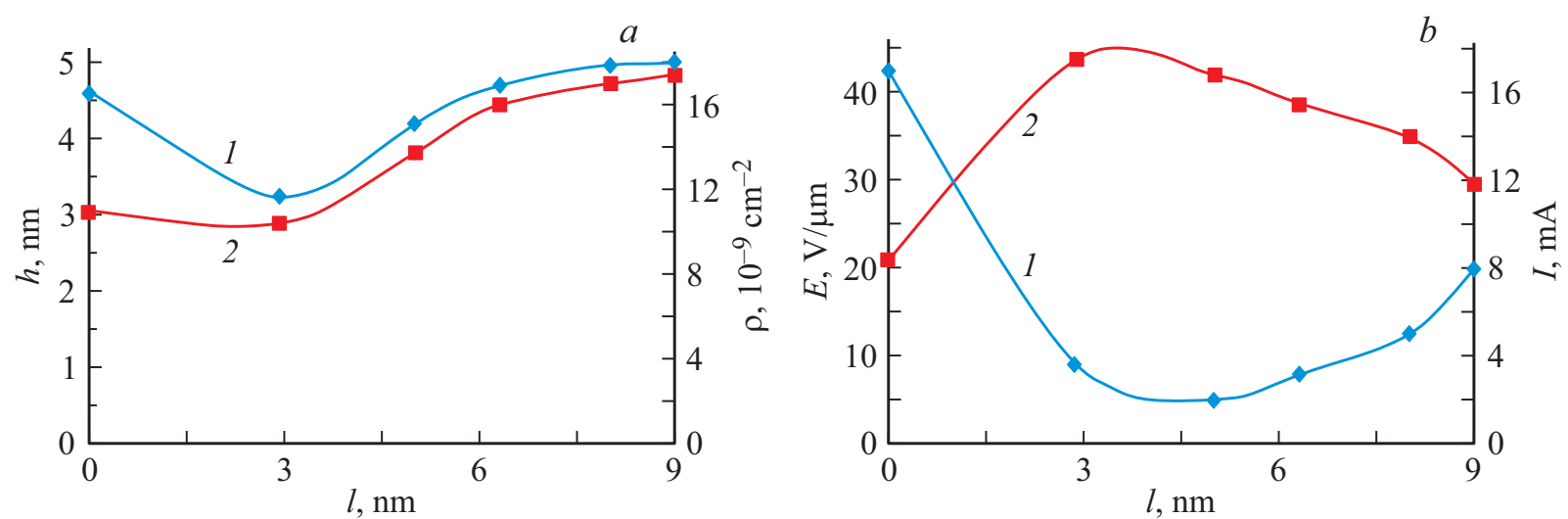

Рис. 2. Зависимости высот (1) и поверхностной плотности

(2) выступов (a), а также порогов (1) и максимальных токов (2) автоэмиссии $(b)$ от толщины алмазной пленки.

P4-SPM-MDT. В качестве зонда использовались стандартные кремниевые кантилеверы CSG10 пирамидальной формы с радиусом закругления $10 \mathrm{~nm}$ и жесткостью $0.1 \mathrm{~N} / \mathrm{m}$. Исследования автоэмиссионных свойств осуществлялись в условиях высокого вакуума $\left(10^{-6} \mathrm{~Pa}\right)$ на диодной структуре, способной изменять расстояние между электродами с точностью до $1 \mu \mathrm{m}$. Диаметр рабочей поверхности анода, изготовленного из углеродного материала МПГ-6, составлял $3 \mathrm{~mm}$. За порог начала автоэмиссии принималась напряженность внешнего электрического поля, при которой плотность автоэмиссионного тока составляла $10 \mu \mathrm{A} / \mathrm{cm}^{2}$.

На рис. 1 приведены АСМ-изображения наноалмазографитовой пленочной структуры до и после осаждения на нее туннельно-тонкого алмазного покрытия, а на рис. 2 представлены зависимости параметров морфологии и автоэмиссии от толщины алмазных покрытий на полученных гетероструктурах. Можно видеть, что при осаждении алмазной пленки толщиной около $3 \mathrm{~nm}$ высоты выступов на гетероструктуре уменьшаются, а их поверхностные плотности остаются неизменными. При этом пороги начала автоэмиссии уменьшаются прак- тически на порядок, а максимальные автоэмиссионные токи увеличиваются более чем в 2 раза. При увеличении толщин алмазных покрытий более $3-5 \mathrm{~nm}$ высоты и поверхностные плотности выступов увеличиваются, а автоэмиссионные характеристики полученных гетероструктур начинают ухудшаться. Максимальная напряженность электрического поля, при которой происходит разрушение катодной матрицы, увеличивается при осаждении алмазной пленки от 65 до $75 \mathrm{~V} / \mu \mathrm{m}$ (порядка 15\%).

Приведенные на рис. 2 результаты экспериментальных исследований влияния толщины тонкой алмазной пленки на морфологию и автоэмиссионные свойства нанокомпозитных алмазографитовых гетероструктур свидетельствуют о том, что взаимосвязь между ними не может быть интерпретирована в рамках известной формулы Фаулера и Нордгейма (ФФН) [5]. В частности, согласно ФФН, со снижением коэффициента усиления поля на отдельных эмитирующих выступах, которое происходит с уменьшением их высоты в результате преимущественного осаждения углерода в углублениях между ними при толщинах алмазной пленки до $3 \mathrm{~nm}$, прозрачность потенциальных барьеров для туннелирова- 


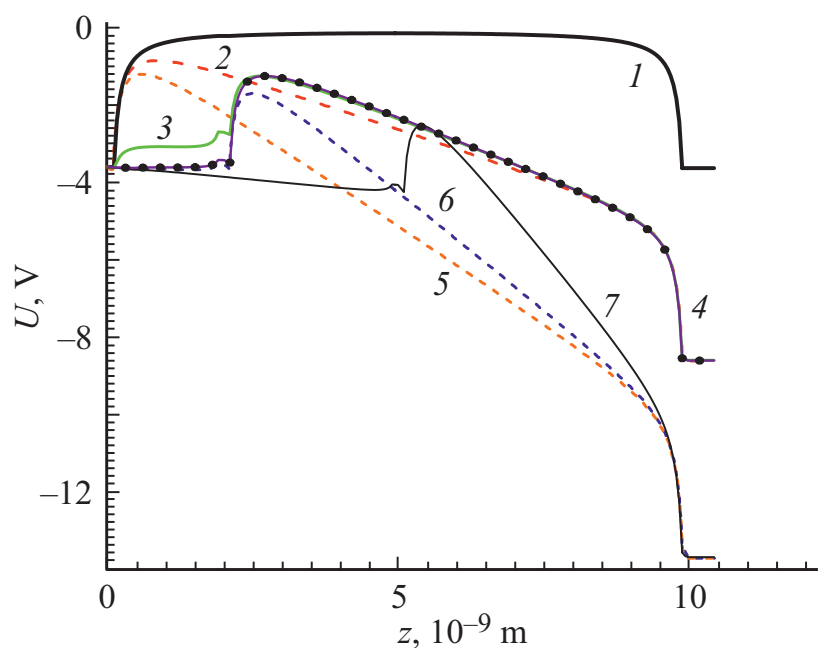

Рис. 3. Распределение потенциала при различных напряжениях на аноде: 1,2,5 - без диэлектрической пленки, 3, 4, 6 - для пленок толщиной $t=2 \mathrm{~nm}, 7-$ для пленки толщиной $t=5 \mathrm{~nm} . V_{A}=0(1), 5(2-4)$ и $10 \mathrm{~V}(5-7) . \varepsilon=4(3), 10$ (7), $12(4,6)$.

ния электронов должна уменьшаться. Вследствие этого пороги начала автоэмиссии должны увеличиваться, а туннельные токи убывать. Однако этот результат ФФН с экспериментом не согласуется. Несоответствие ФФН имеет место для всех толщин осажденных алмазных покрытий. Так, с увеличением толщин алмазных пленок в интервале от 5 до $8 \mathrm{~nm}$ высоты выступов и пороги начала автоэмиссии увеличиваются одновременно, что также противоречит ФФН.

Согласно теории Фаулера-Нордгейма, величина потенциального барьера (ПБ), удерживающего электроны в материале автокатода, определяется внешним электрическим полем и силами зеркального изображения [5]. Чем сильнее превышение сил внешнего электрического поля над силами зеркального изображения, тем у́же и ниже ПБ, что приводит к экспоненциальному увеличению коэффициента туннелирования электронов. В настоящее время увеличение разности между этими силами реализуется за счет увеличения напряженности внешнего поля, которое достигается применением различных высокотехнологичных конструктивных решений, направленных на повышение фактора усиления поля на эмиссионных центрах. Это реализуется путем изготовления высокоаспектных эмиттеров, уменьшения радиусов эмитирующих острий, диаметров отверстий в управляющих электродах и т. д. [6,7]. Однако, как показывает практика, большие напряженности электрических полей одновременно с повышением эффективности полевой эмиссии ослабляют электрическую прочность и уменьшают долговечность и стабильность эмиссии автокатодов. С другой стороны, превышение сил внешнего электрического поля над силами зеркального изображения можно обеспечить уменьшением последних. Силы зеркального изображения, обусловленные кулоновским взаимодействием эмитирующих электронов с наведенным зарядом внутри автокатода, можно ослабить, если между взаимодействующими зарядами расположить слой диэлектрика. Радиус действия сил зеркального изображения, как известно, ограничивается несколькими межатомными расстояниями. Поэтому слой диэлектрика должен быть достаточно тонким. При толщинах диэлектрика, превышающих радиус действия сил зеркального изображения, он будет преимущественно ослаблять напряженность внешнего электрического поля. Уменьшение разности между указанными электрическими силами вновь приведет к уменьшению прозрачности потенциального барьера и ухудшению параметров автоэмиссии.

Исходя из этих представлений теоретически на основе классического подхода рассмотрено влияние на туннельный ток тонких диэлектрических и полупроводниковых покрытий с низкой проводимостью и высокой диэлектрической проницаемостью, выполненных на проводящем катоде в плоской диодной структуре [2]. Показано влияние таких структур на холодную эмиссию, при этом сравнимая по толщине с барьером тонкая пленка с большой диэлектрической проницаемостью существенно ее увеличивает, особенно при не очень больших по сравнению с ее толщиной расстояниях катод-анод. Эффект от изменения работы выхода является наиболее сильным, если толщина пленки порядка ширины потенциального барьера в ее отсутствие, при этом промежуток $d$ катод-анод составляет 2-3 толщины пленки. На рис. 3 показаны результаты расчета изменения профиля барьера при приложении анодного напряжения для пленок толщиной 2 и $5 \mathrm{~nm}$ с различными проницаемостями и в случае их отсутствия. Можно видеть, что в присутствии диэлектрических пленок на границе катод-пленка барьера практически нет. Более узкий и низкий барьер по сравнению со случаем отсутствия диэлектрической пленки возникает только на границе диэлектрическая пленка-вакуум.

Таким образом, большая диэлектрическая проницаемость алмазного покрытия $(\varepsilon=16.5$ [8]) приводит к локальному ослаблению сил зеркального изображения и соответственно уменьшению потенциального барьера на границе катод-алмазная пленка. Это способствует уменьшению высоты и ширины потенциальных барьеров для туннелирования электронов на границе катод с алмазной пленкой-вакуум (такой ПБ оказывается существенно ниже и у́же, чем у границы металл-вакуум). Интегральным результатом является уменьшение порогов начала полевой эмиссии и увеличение туннельного тока при сохранении прежней величины внешнего электрического поля. При получении одинакового автоэмиссионного тока уменьшается полевая нагрузка на кристаллическую решетку нанокомпозитной алмазографитовой автоэмиссионной структуры и увеличиваются стабильность и долговечность автокатода. Последнее обусловлено тем, что в гетероструктуре с тонкой алмазной пленкой при одинаковой напряженности внешнего электрического поля за счет падения напряжения на 
ней уменьшается электростатический поверхностный потенциал на композитной алмазографитовой пленке. Вследствие повышения прозрачности ПБ он может оставаться достаточным для туннельной эмиссии электронов с прежней плотностью тока. Из-за статистической неоднородности высот выступов алмазографитовой пленки и коэффициентов усиления поля на них на вершинах недостаточно высоких выступов и в прилегающих к ним участках тонкой алмазной пленки вследствие дрейфа электронов при импульсных воздействиях сильных электрических полей положительной полярности формируются области отрицательного пространственного заряда. При длительных импульсных воздействиях напряженность поля на участках пленки с областями отрицательного пространственного заряда может превысить пробойное значение. Поскольку электрическая прочность алмазного покрытия выше, чем у алмазографитового, электрический пробой происходит при более высоких напряженностях электрических полей. Кроме снижения порогов начала полевой эмиссии электронов увеличение стабильности автоэмиссии и долговечности алмазографитовых катодных структур обусловлено также увеличением теплопроводности и устойчивости к ионному распылению осажденной алмазной пленки при эксплуатации в условиях технического вакуума и высоковольтного питания.

\section{Финансирование работы}

Экспериментальная часть работы выполнена в рамках государственного задания. Теоретическая интерпретация проведена с использованием результатов, полученных в рамках гранта Российского научного фонда № 16-1910033.

\section{Конфликт интересов}

Автор заявляет, что у него нет конфликта интересов.

\section{Список литературы}

[1] Фурсей Г.Н., Поляков М.А., Кантонистов А.А., Яфясов А.М., Павлов Б.С., Божевольнов В.Б. // ЖТФ. 2013. T. 83. В. 6. С. $71-77$.

[2] Давидович М.В., Яфаров Р.К. // ЖТФ. 2018. Т. 88. В. 2. C. 283-293.

[3] Ябаров Р.К. // Радиотехника и электроника. 2019. Т. 64. № 12. C. $1238-1243$.

[4] Яфаров Р.К. Физика СВЧ вакуумно-плазменных нанотехнологий. М.: Физматлит, 2009. $216 \mathrm{c.}$

[5] Fowler R.H., Nordheim L.W. // Proc. Roy. Soc. Lond. A. 1928. V. 119. N 781. P. 173-179.

[6] Marcus R.B., Ravi T.S., Gmitter T., Chin K., Liu D., Orvis W.J., Ciarlo D.R., Hunt C.E., Trujillo J. // Appl. Phys. Lett. 1990. V. 56. N 3. P. $236-238$.

[7] Velásquez-García L.F., Guerrera S., Niu Y., Akinwande A.I. // IEEE Trans. Electron Dev. 2011. V. 58. N 6. P. 1783-1789.

[8] Forouhi A.R., Bloomer I. // Phys. Rev. B. 1988. V. 38. N 3. P. 1865-1874. 